\title{
Programmed cell death in mature erythrocytes: a model for investigating death effector pathways operating in the absence of mitochondria
}

\author{
D Bratosin ${ }^{1,2}$, J Estaquier ${ }^{3}$, F Petit ${ }^{3}$, D Arnoult ${ }^{3}$, \\ B Quatannens ${ }^{4}$, J-P Tissier ${ }^{5}$, C Slomianny ${ }^{5}$, C Sartiaux ${ }^{6}$, \\ C Alonso $^{6}$, J-J Huart ${ }^{6}$, J Montreuil ${ }^{\star, 2}$ and JC Ameisen ${ }^{\star, 3}$ \\ ${ }^{1}$ National Institute for Biological Science Research and Development, \\ Bucharest, Rumania \\ 2 Université des Sciences et Technologies de Lille, CNRS UMR 8576, 59655 \\ Villeneuve d'Ascq Cedex, France \\ ${ }^{3}$ EMI-U 9922 INSERM-Universite Paris 7, IFR02, AP-HP, Hopital Bichat-Claude \\ Bernard, 75877 Paris cedex 18, France \\ ${ }^{4}$ Institut de Biologie de Lille, 59000 Lille, France \\ 5 INRA/LGPTA, 59651 Villeneuve d'Ascq, France \\ ${ }^{6}$ Etablissement Regional de Transfusion Sanguine, 59000 Lille, France \\ * Corresponding authors: Jean-Claude Ameisen, INSERM EMI-U 9922, CHU \\ Bichat-Claude Bernard, 46 rue Henri Huchard, 75877 Paris cedex 18, France. \\ Tel: +33 1402586 01; Fax: +33 1402586 02; E-mail: ants@club-internet.fr \\ or Jean Montreuil, CNRS UMR 8576, USTL, 59655 Villeneuve d'Ascq Cedex, \\ France. Tel: +33 3204348 84; Fax: +33 3204365 55; \\ E-mail: jean.montreuil@univ-lille1.fr
}

Received 25.6.01; revised 20.8.01; accepted 20.8.01

Edited by G Melino

\begin{abstract}
Human mature erythrocytes have been considered as unable to undergo programmed cell death (PCD), due to their lack of mitochondria, nucleus and other organelles, and to the finding that they survive two conditions that induce PCD in vitro in all human nucleated cells, treatment with staurosporine and serum deprivation. Here we report that mature erythrocytes can undergo a rapid self-destruction process sharing several features with apoptosis, including cell shrinkage, plasma membrane microvesiculation, phosphatidylserine externalization, and leading to erythrocyte disintegration, or, in the presence of macrophages, to macrophage ingestion of dying erythrocytes. This regulated form of PCD was induced by $\mathrm{Ca}^{2+}$ influx, and prevented by cysteine protease inhibitors that allowed erythrocyte survival in vitro and in vivo. The cysteine proteinases involved seem not to be caspases, since (i) proforms of caspase 3 , while present in erythrocytes, were not activated during erythrocyte death; (ii) cytochrome $c$, a critical component of the apoptosome, was lacking; and (iii) cell-free assays did not detect activated effectors of nuclear apoptosis in dying erythrocytes. Our findings provide the first identification that a death program can operate in the absence of mitochondria. They indicate that mature erythrocytes share with all other mammalian cell types the capacity to selfdestruct in response to environmental signals, and imply that erythrocyte survival may be modulated by therapeutic intervention. Cell Death and Differentiation(2001) 8,1143-1156.
\end{abstract}

Keywords: mature erythrocytes; programmed cell death; apoptosis; mitochondria; phosphatidylserine exposure; caspase 3

Abbreviations: AIF, apoptosis inducing factor; CAD, caspaseactivated DNase; $P C D$, programmed cell death

\section{Introduction}

Programmed cell death (PCD) is a genetically regulated process of self-destruction whose most frequent phenotype is apoptosis, characterized by a series of stereotyped changes affecting the nucleus, cytoplasm and plasma membrane, and leading to the dismantling of the dying cell and to its rapid ingestion by macrophages or other neighboring cells. ${ }^{1-3}$ In mammalian cells, PCD depends on two major executionary pathways, that usually operate together and amplify each other. One involves the proteolytic activation of a family of aspartate-directed cysteine proteinases, the effector caspases; the other one involves mitochondrial outer membrane permeabilization, leading to the release in cytosol of mitochondrial pro-apoptotic proteins that either induce caspase activation, such as cytochrome $c$ and Smac/Diablo, or that trigger caspase-independent effectors pathways such as apoptosis-inducing factor AIF., ${ }^{1,4-7}$ With the possible exception of direct caspase 8 activation by the engagement of cell surface death receptors of the CD95/tumor necrosis factor receptor family, ${ }^{8}$ most, if not all, pro-apoptotic stimuli appear to require a mitochondrion-dependent step. ${ }^{1,2,4-7}$ Therefore, mitochondria have been proposed to play a central role in PCD. ${ }^{5-7,9,10}$ Recent knock-out experiments of genes encoding cytochrome $c^{11}$ or $\mathrm{AlF}^{12}$ have indicated that each of these intramitochondrial proteins is required for the induction of PCD in response to some but not all pro-apoptotic stimuli. Until now, however, PCD has only been investigated in cells that contain mitochondria. These include nucleated cells, ${ }^{2,13,14}$ cytoplast artificially obtained by removing the nucleus, ${ }^{15,16}$ and a cell type naturally devoid of nucleus, the blood platelet, that has recently been reported to undergo a caspase-independent apoptotic-like activation-induced cell death. ${ }^{17}$ No experiments have yet addressed whether PCD can occur in the absence of mitochondria.

Human mature erythrocytes are terminally differentiated cells of the erythroid lineage, that are devoid of mitochondria, as well as of nucleus and other organelles, and have a normal life span of 120 days that is ended by a process of senescence leading to their clearance from the peripheral blood by reticuloendothelial cells. ${ }^{18-20}$ Erythrocyte senescence is associated with cell shrinkage, plasma membrane microvesiculation, a progressive shape change from a discocyte to a spherocyte, cytoskeleton alterations associated with protein (spectrin) degradation, and loss of 
plasma membrane phospholipid asymmetry leading to the externalization of phosphatidylserine, that may represent one of the signals allowing macrophages to ingest the senescent erythrocytes. ${ }^{18-23}$ In vitro storage of erythrocytes leads to the gradual accumulation of these modifications, and ex vivo, a very small subpopulation of human erythrocytes with a senescent phenotype can be isolated from the peripheral blood. ${ }^{19,20,23}$ Despite the similarities between this senescent phenotype and some cytoplasmic features of apoptosis, mature erythrocytes have been considered as the sole mammalian cell lacking the machinery required to undergo PCD, because they survive two conditions that induce PCD in all human nucleated cells studied so far, i.e. treatment with the protein kinase inhibitory drug staurosporine, and culture in the absence of serum or other potential survival-promoting factors. ${ }^{14}$

We reasoned that the absence of response of erythrocytes to staurosporine and to serum deprivation was not sufficient to exclude the existence of a death machinery allowing erythrocytes to self-destruct in response to environmental changes, and that erythrocyte senescence may represent a particular, time-dependent outcome of the induction of such a self-destruction program. Indeed, the normal life span and senescence of several terminally differentiated nucleated cells is controlled by a time-dependent process of PCD induction, that can be either accelerated or delayed by environmental signals.

Since erythrocyte senescence has been reported to be associated with a progressive increase in intracellular calcium $\left(\mathrm{Ca}^{2+}\right),{ }^{24,25}$ we decided to investigate whether $\mathrm{Ca}^{2+}$ entry into freshly isolated human erythrocytes may suffice to induce premature erythrocyte death.

Here we report that a regulated form of self-destruction, sharing several features with apoptosis, can be rapidly induced in mature erythrocytes by calcium influx, and can be prevented by inhibitors of cysteine proteinases, that allow erythrocytes to survive in vitro and in vivo. This regulated cell death process, that operates in the absence of mitochondria and cytochrome $c$, appears not to require caspase activation.

These findings indicate that erythrocytes constitutively express a death machinery capable of inducing several of the cytoplasmic and plasma membrane changes associated with apoptosis and suggest that erythrocyte survival may be modulated in vitro and in vivo by therapeutic intervention.

\section{Results}

\section{A rapid calcium-dependent erythrocyte death process with several features of apoptosis}

Erythrocyte death and disintegration Human mature erythrocytes freshly isolated and purified from peripheral blood of healthy donors were incubated with the calciumionophore A $23187(0.5 \mu \mathrm{M})$ in the presence of extracellular $\mathrm{Ca}^{2+}(2.5 \mathrm{mM})$. This treatment led to a rapid and complete disappearance of the cells in $48 \mathrm{~h}$ (Figure 1A), that was associated with a rapid and sharp increase in the extracellular release of hemoglobin (hemolysis) (Table 1). The kinetics of $A$ 23187-induced erythrocyte death were dose-dependent (data not shown).

A 23187 did not induce cell death in the absence of extracellular $\mathrm{Ca}^{2+}$, nor in the presence of both $\mathrm{Ca}^{2+}$ and the $\mathrm{Ca}^{2+}$ chelator EDTA (5 mM) (data not shown), indicating that erythrocyte death was an active process requiring $\mathrm{Ca}^{2+}$ entry into the cells. As also shown in Figure 1A, incubation of human erythrocytes with $\mathrm{Ca}^{2+}(2.5 \mathrm{mM})$ alone, in the absence of A 23187, induced a much slower death process, that only began to induce erythrocyte disintegration after $48 \mathrm{~h}$, and required 6 days to lead to the disappearance of more than $80 \%$ of the erythrocytes. When erythrocytes were incubated in the absence of extracellular $\mathrm{Ca}^{2+}$, or in the presence of both $\mathrm{Ca}^{2+}$ and the $\mathrm{Ca}^{2+}$ chelator EDTA, all cells survived during the 6 day period (Figure 1A). Finally, we confirmed the previously reported finding that staurosporine does not induce erythrocyte death. ${ }^{14}$ Indeed, as shown in Figure 1A, erythrocytes survived during 6 days after incubation with staurosporine $(10 \mu \mathrm{M})$ in the absence of extracellular $\mathrm{Ca}^{2+}$, and in the presence of extracellular $\mathrm{Ca}^{2+}$, erythrocyte death was neither accelerated nor increased by staurosporine. In all subsequent experiments, the concentrations of $A 23187$ $(0.5 \mu \mathrm{M}), \mathrm{Ca}^{2+}(2.5 \mathrm{mM})$ and staurosporine $(10 \mu \mathrm{M})$ used were the same.

Morphological changes Scanning electron microscopy showed that $\mathrm{Ca}^{2+}$-induced erythrocyte death was preceded by dramatic morphological changes (Figure 1B). Indeed, $3.5 \mathrm{~h}$ after $\mathrm{A} 23187$ treatment in the presence of $\mathrm{Ca}^{2+}$, or 2 days after incubation with $\mathrm{Ca}^{2+}$ alone, the shape of erythrocytes changed from normal discocytes to echinocytes or spheroechinocytes, ${ }^{21}$ with plasma membrane microvesiculation. As also shown in Figure 1B, these rapid morphological changes induced by $\mathrm{Ca}^{2+}$ in vitro were identical to the features expressed by the very small subpopulation of in vivo senescent erythrocytes (less than $1 \%$ of the erythrocytes) that we purified from peripheral blood of healthy donors. ${ }^{23}$ In contrast, almost all erythrocytes incubated for $24 \mathrm{~h}$ with staurosporine in the absence of $\mathrm{Ca}^{2+}$ remained in their normal discoid shape, with a few cells only becoming cup-shaped stomatocytes, ${ }^{21}$ and no cells undergoing echinocyte or spheroechinocyte transformation nor showing plasma membrane microvesiculation.

Flow-cytometry analysis indicated that the morphological changes induced either by $\mathrm{A} 23187$ in the presence of $\mathrm{Ca}^{2+}$ or by $\mathrm{Ca}^{2+}$ alone were associated with cell shrinkage (decreased forward scatter and increased side scatter) (Figure 1C), one of the characteristic features of apopto$\operatorname{sis}^{1,26,27}$ that distinguishes this active and regulated selfdestruction process from the passive and chaotic process of necrosis induced by plasma membrane damage.

Phosphatidylserine externalization Flow-cytometry analysis using labeled Annexin $\mathrm{V}$ indicated that incubation of human mature erythrocytes with $\mathrm{A} 23187$ in the presence of $\mathrm{Ca}^{2+}$, or with $\mathrm{Ca}^{2+}$ alone, induced a rapid phosphatidylserine externalization (Figure 1C), a feature characteristic of both 
apoptosis in nucleated cells s,28 $^{3,28}$ of senescence in erythrocytes. ${ }^{19,23,28}$ A 23187 - or $\mathrm{Ca}^{2+}$-treated erythrocytes that bound labeled Annexin V, did not bind two labeled control lectins of similar molecular weight, PNA and GNA (data not shown), indicating that Annexin $\mathrm{V}$ binding was specific for phosphatidylserine exposure on the outer leaflet of the plasma membrane, and was not a consequence of plasma membrane damage that would allow the indiscriminate binding or entry of any labeled protein.

Erythrocyte capture and ingestion by macrophages Phosphatidylserine exposure on the outer leaflet of the plasma membrane is one of the signals that allow macrophages to bind and ingest apoptotic cells, ${ }^{3,28}$ as well as senescent erythrocytes. ${ }^{23}$ During apoptosis, ingestion of the dying cells by macrophages is an early event that precedes the disintegration of these dying cells that will occur in the absence of macrophages. ${ }^{3}$

In the absence of macrophages, A 23187-treated erythrocytes disintegrated in $48 \mathrm{~h}$ (Figure 1A). In the presence of macrophages, however, A 23187 pre-treated erythrocytes were rapidly captured and ingested by macrophages $3 \mathrm{~h}$ after having been incubated with $A$ 23187 , as shown by scanning electron microscopy analysis of erythrocyte binding to macrophages (Figure $2 \mathrm{~A}$ ), and by flow cytometry analysis of macrophages that had been incubated with erythrocytes pre-labeled with the lipophilic cationic agent $\mathrm{PKH}-26$ (Figure 2B). Incubation of erythrocytes with $\mathrm{Ca}^{2+}$ alone, in the absence of $A 23187$ also led to their capture (data not shown) and ingestion (Figure 2B) by macrophages at a time point $(48 \mathrm{~h})$ that preceded by several days the disintegration of erythrocytes that occurred in response to $\mathrm{Ca}^{2+}$ in the absence of macrophages (Figure 1A). In contrast, erythrocytes that had been incubated for $48 \mathrm{~h}$ in the absence of $\mathrm{Ca}^{2+}$ were neither captured (Figure 2A) nor ingested (Figure 2B) by macrophages. Together, these data indicated that human mature erythrocytes can undergo a rapid and orderly $\mathrm{Ca}^{2+}$-dependent death process sharing several features with apoptosis and leading either to an early elimination of the dying cells through ingestion by neighboring macrophages, or, in the absence of macrophages, to a more progressive elimination of the dying cells through self-disintegration.

\section{Cysteine proteinase inhibitors prevent $\mathrm{Ca}^{2+}$-dependent erythrocyte death}

Caspases are a family of aspartate-directed cysteine proteinases that are crucial effectors of apoptosis, ${ }^{1,4,29,30}$ and calpain is another $\mathrm{Ca}^{2+}$-dependent cysteine proteinase that has been reported to also participate in apoptosis ${ }^{31,32}$ and to be involved in a $\mathrm{Ca}^{2+}$-induced apoptosis-like death process of blood platelets. ${ }^{17}$ For these reasons, we investigated whether $\mathrm{Ca}^{2+}$-induced erythrocyte death may depend on the activation of cysteine proteinases, by exploring the effect of Ac-DEVD-CHO, an inhibitor of Caspase 3, one of the main effector caspases involved in the execution of apoptosis, , 29,30 and of leupeptin, a broad inhibitor of cysteine proteinases, including calpain.
Prevention of erythrocyte disintegration Human mature erythrocytes were incubated with $A 23187$ and $\mathrm{Ca}^{2+}$ in the absence or presence of Ac-DEVD-CHO, leupeptin, or a mixture of both. As shown in Table 1, each inhibitor alone, as well as the mixture of both, led to a very significant inhibition of the release of extracellular hemoglobin (hemolysis), with more than 85 and $75 \%$ inhibition of erythrocyte death 8 and $20 \mathrm{~h}$, respectively, after the addition of $\mathrm{A} 23187$ and $\mathrm{Ca}^{2+}$. In nucleated cells, Ac-DEVD-CHO and leupetin have been reported to exert optimal preventive effects on their cysteine proteinase targets at concentrations of $100 \mu \mathrm{M}$. While they exerted a significant preventive effect on erythrocyte death at concentrations of $100 \mu \mathrm{M}$, the optimal preventive effects shown in Table 1 were obtained using concentrations of $200 \mu \mathrm{M}$. This suggested either that the intracellular entry of these inhibitors was less effective in erythrocytes than in nucleated cells, or that the cysteine proteinases on which they acted in erythrocytes were not their specific targets. It should be noted, however, that $100 \mu \mathrm{M}$ of cystein proteinase inhibitor is usually used as an optimal concentration in cell cultures of $10^{6}$ cells $/ \mathrm{ml}$, while we used $200 \mu \mathrm{M}$ in erythrocyte cultures of $10^{7}$ cells $/ \mathrm{ml}$, i.e. 10 times more cells per volume unit. Thus, while the number of inhibitor molecules per volume unit was twice the optimal usually used, the number of inhibitor molecules per cell was only a fifth. Finally, in contrast to the preventive effect of the two cysteine proteinase inhibitors, an inhibitor of serine proteinases, tosyl-LYS-cmk, at the same $200 \mu \mathrm{M}$ concentration, had no preventive effect on A 23187induced erythrocyte death (data not shown). We decided to use the cysteine proteinase inhibitors in the further experiments at the same concentrations that had shown an optimal preventive effect on erythrocyte death.

Prevention of phosphatidylserine externalization Flow cytometry analysis of annexin- $\mathrm{V}$-labeling indicated that treatment with Ac-DEVD-CHO, leupeptin or a mixture of both, almost completely inhibited erythrocyte phosphatidylserine externalization induced by $3 \mathrm{~h}$ incubation with A 23187 and $\mathrm{Ca}^{2+}$ or by 3 days incubation with $\mathrm{Ca}^{2+}$ alone (Figure 3 and Table 2). In contrast, tosyl-LYS-cmk had no significant preventive effect on PS externalization (Table 2).

Prevention of morphological changes Treatment with the cysteine-proteinase inhibitors also prevented erythrocyte shrinkage induced by $\mathrm{A} 23187$ and $\mathrm{Ca}^{2+}$, or by $\mathrm{Ca}^{2+}$ alone, as assessed by flow cytometry (Figure 3 ), and allowed erythrocytes to maintain their discoid shape, as assessed by scanning electron microscopy (Figure 4). A typical picture of discoid erythrocytes without plasma membrane microvesicles $48 \mathrm{~h}$ after incubation with $\mathrm{Ca}^{2+}$ and Ac-DEVD-CHO is shown in Figure 4, while in the absence of the inhibitor, erythrocytes became spheroechinocytes with plasma membrane microvesicles, or smooth spherocytes.

Prevention of erythrocyte capture and ingestion by macrophages Treatment of erythrocytes with $\mathrm{A} 23187, \mathrm{Ca}^{2+}$, and cysteine proteinase inhibitors exerted an inhibitory effect on 
A
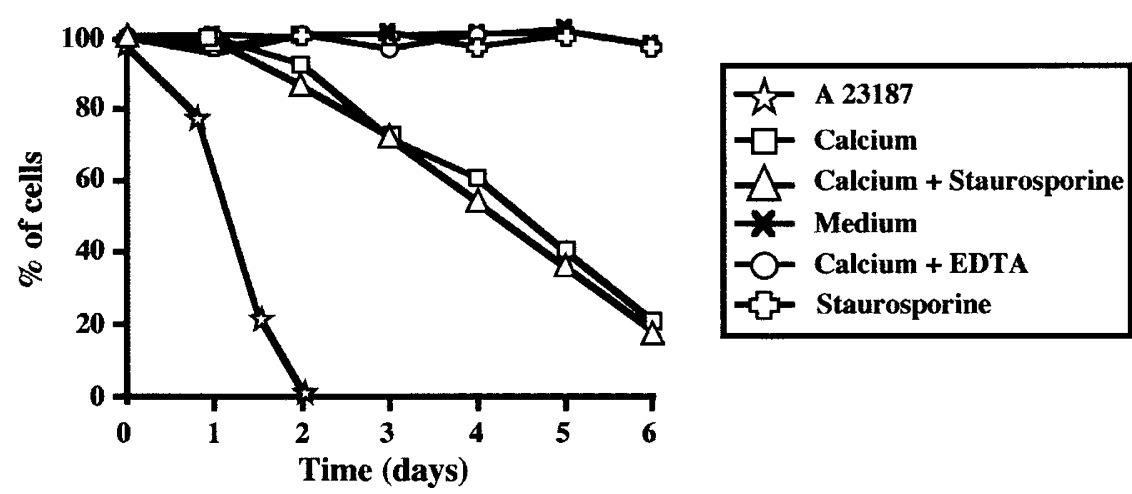

B
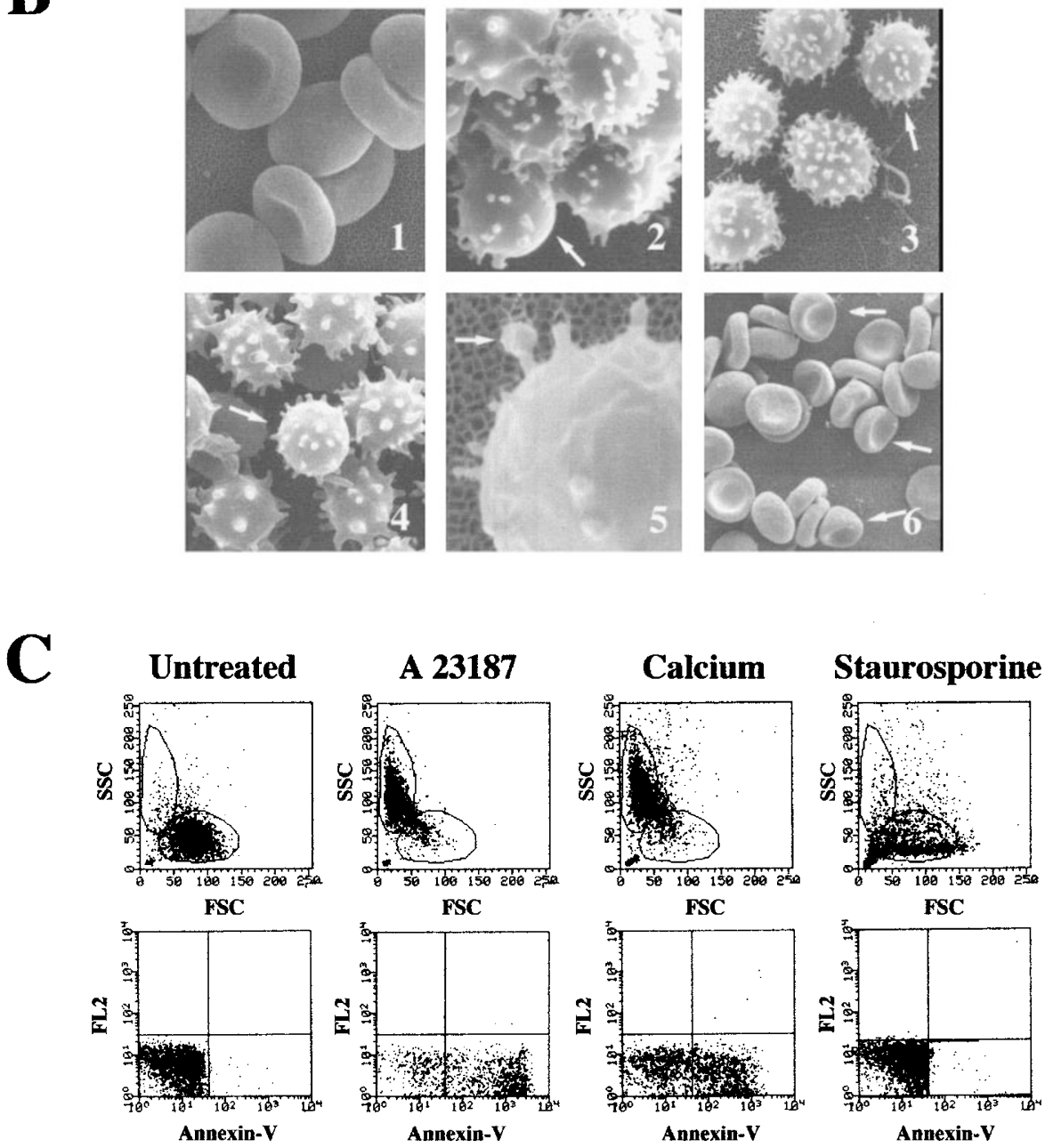

Figure 1 Morphological changes, phosphatidylserine exposure and cell death induced by calcium ionophore and calcium in human mature erythrocytes. (A) Cell death. Freshly isolated and purified mature human erythrocytes were incubated either with the calcium ionophore $\mathrm{A} 23187(0.5 \mu \mathrm{M})$ in the presence of $\mathrm{Ca}^{2+}$ $(2.5 \mathrm{mM})$; or with $\mathrm{Ca}^{2+}(2.5 \mathrm{mM})$ in the absence or presence of staurosporine $(10 \mu \mathrm{M})$; or with medium alone, in the absence of $\mathrm{Ca}^{2+} ;$ or with $\mathrm{Ca}^{2+}(2.5 \mathrm{mM})$ and the calcium chelator EDTA $(5 \mathrm{mM})$; or with staurosporine $(10 \mu \mathrm{M})$ in the absence of $\mathrm{Ca}^{2+}$. Per cent of cells indicate the percentages of erythrocytes remaining in the culture at the indicated time points. (B) Scanning electron microscopy analysis of morphological changes. Freshly isolated and purified human erythrocytes after $48 \mathrm{~h}$ incubation in medium alone, in the absence of $\mathrm{Ca}^{2+}(1)$; or after $3 \mathrm{~h}$ incubation with $\mathrm{A} 23187$ and $\mathrm{Ca}^{2+}(3)$; or after $48 \mathrm{~h}$ incubation with $\mathrm{Ca}^{2+}$ alone $(4)$; or after $24 \mathrm{~h}$ incubation with staurosporine in the absence of $\mathrm{Ca}^{2+}(6)$. (2) A small subpopulation $(<1 \%)$ of senescent erythrocytes, purified from freshly isolated human mature erythrocytes by a self-forming Percoll gradient, ${ }^{23}$ shows the same morphological features as A 23187 and $\mathrm{Ca}^{2+}$-treated (3) or $\mathrm{Ca}^{2+}$-treated (4) erythrocytes. (5) Close-up from (4) showing a microvesicle in formation (arrow). In (2-4) the arrows show a typical spheroechinocyte. In (6), arrows show cup-shaped erythrocytes (stomatocytes). (C) Flow cytometry analysis of shape changes and phosphatidylserine exposure. Freshly isolated and purified human mature erythrocytes were analyzed after either $48 \mathrm{~h}$ incubation in medium alone, in the absence of $\mathrm{Ca}^{2+}$ (Untreated); or $3 \mathrm{~h}$ incubation with $\mathrm{A} 23187$ and $\mathrm{Ca}^{2+}$ (A 23187 ); or $48 \mathrm{~h}$ incubation with $\mathrm{Ca}^{2+}$ alone (calcium); or $24 \mathrm{~h}$ incubation with staurosporine, in the absence of $\mathrm{Ca}^{2+}$ (staurosporine). Top boxes: Shape changes; dot Blot 
their further capture (Figure 2A and Table 3) and ingestion (Figure 2B and Table 3 ) by macrophages. In contrast, when macrophages were pretreated with the cysteine proteinase inhibitors, and subsequently incubated with A 23187- and $\mathrm{Ca}^{2+}$-pretreated erythrocytes, neither capture nor ingestion by macrophages were prevented (data not shown), indicating that the inhibitors exerted their preventive effect on the erythrocytes and did not affect the capacity of macrophages to capture and to ingest dying erythrocytes.

\section{In vitro treatment with cysteine proteinase inhibitors allows in vivo survival of $\mathrm{Ca}^{2+}$-activated murine erythrocytes}

Murine mature erythrocytes freshly purified from BALB/c mice were incubated in vitro for 4 days with $\mathrm{Ca}^{2+}$, in the absence or presence of Ac-DEVD-CHO, leupeptin, or a mixture of both. As we observed with human erythrocytes, incubation with each inhibitor alone, or with a mixture of both, very effectively prevented PS externalization by murine erythrocytes (Table 4). In order to be able to subsequently follow the in vivo survival in the blood circulation of the treated erythrocytes, we labeled them with $\mathrm{PKH}-26$ prior to injection in recipient mice. As a control, untreated freshly isolated murine erythrocytes were also labeled with $\mathrm{PKH}-26$. The labeled treated and untreated erythrocytes $\left(10^{9}\right.$ erythrocytes per recipient mouse) were then injected intravenously in syngeneic BALB/c recipient mice. Erythrocytes that had been incubated in vitro with $\mathrm{Ca}^{2+}$ in the absence of cysteine proteinase inhibitor were almost completely cleared from the circulation $48 \mathrm{~h}$ after injection. On the contrary, erythrocytes that had been incubated in vitro with $\mathrm{Ca}^{2+}$ in the presence of Ac-DEVD$\mathrm{CHO}$, leupeptin or a mixture of both, remained in the circulation for at least $48 \mathrm{~h}$ at the same level as the freshly isolated untreated control erythrocytes. Results from two different representative experiments are shown in Figure 5 and Table 4 . In both experiments, a small and progressive decrease in the numbers of labeled untreated control erythrocytes in the circulation was observed, that may be due both to the physiological clearance of the murine erythrocytes, whose normal life span in vivo is 40 days, and to the in vitro procedures used to purify and to label the cells. As shown in Figure 5 and Table 4, 94 and $86 \%$, respectively of the labeled untreated control erythrocytes detected in the circulation $1 \mathrm{~h}$ after injection were still present $48 \mathrm{~h}$ later. The numbers of erythrocytes that had been treated in vitro with $\mathrm{Ca}^{2+}$ and a mixture of both cysteine proteinase inhibitors and that remained in the circulation $48 \mathrm{~h}$ after injection was identical (Figure 5) or almost identical (Table 4) to the numbers of untreated control erythrocytes. In contrast, when compared to untreated control erythrocytes, only around $20 \%$ (Figure 5) and 10\% (Table 4) of erythrocytes treated with $\mathrm{Ca}^{2+}$ in the absence of inhibitor were detected in the circulation $1 \mathrm{~h}$ after injection, and less than 3\% $48 \mathrm{~h}$ after injection.

Together, our data indicated that a form of $\mathrm{Ca}^{2+}$-dependent apoptosis-like cell death process can be induced in mature erythrocytes, and that cysteine proteinase inhibitors are able to prevent this death process and to allow subsequent erythrocyte survival both in vitro and in vivo.

\section{Proforms of caspase 3 are present in human mature erythrocytes, but are not activated during $\mathrm{Ca}^{2+}$-dependent death}

In mature erythrocytes, the presence of the calpain cysteine proteinase has been documented ${ }^{33}$ but the existence of caspases has never been investigated.

Caspases are synthesized as inactive proforms, that are activated after proteolytic cleavage. In nucleated cells, most, if not all, of the pro-apoptotic stimuli cause the mitochondrial release of cytochrome $c$ in the cytosol, required for the formation of the apoptosome, that induces caspase 9 activation, and leads to the activation of the effector caspase $3^{1,4,6}$ We investigated whether erythrocytes contain caspase 3 and cytochrome $c$. Erythrocyte extracts were subjected to Western blotting with antibodies

Table 1 Preventive effect of cysteine proteinase inhibitors on human mature erythrocyte death (hemolysis) induced by calcium ionophore

\begin{tabular}{|c|c|c|c|c|}
\hline \multirow[b]{2}{*}{$\begin{array}{l}\text { lonophore A } 23187 \text { treated human } \\
\text { erythrocytes }\end{array}$} & \multicolumn{4}{|c|}{ Hemolysis } \\
\hline & $\begin{array}{l}\text { Incubation time } \\
\qquad 8 \mathrm{~h}\end{array}$ & $\begin{array}{c}\text { Inhibition } \\
\%\end{array}$ & $\begin{array}{l}\text { Incubation time } \\
\qquad 20 \mathrm{~h}\end{array}$ & $\begin{array}{c}\text { Inhibition } \\
\%\end{array}$ \\
\hline $\begin{array}{l}\text { In the absence of inhibitor } \\
\text { In the presence of inhibitors }\end{array}$ & $60 \mu \mathrm{g}^{\star}$ & - & $195 \mu \mathrm{g}$ & - \\
\hline Ac-DEVD-CHO & $7 \mu \mathrm{g}$ & 88 & $46 \mu \mathrm{g}$ & 76 \\
\hline Leupeptin & $9 \mu \mathrm{g}$ & 85 & $27 \mu \mathrm{g}$ & 86 \\
\hline Leupeptin+Ac-DEVD-CHO & $8 \mu \mathrm{g}$ & 86 & $32 \mu \mathrm{g}$ & 83 \\
\hline
\end{tabular}

Erythrocytes were incubated with A 23187 and $\mathrm{Ca}^{2+}$ in the absence or presence of pretreatment for 30 min with Ac-DEVD-CHO, leupeptin or a mixture of both, and hemolysis was assessed by measuring the extracellular release of haemoglobin. Results presented are from one representative experiment out of three. ${ }^{\star}$ Extracellular haemoglobin ( $\mu \mathrm{g}$ per medium liter)

analysis of Forward scatter versus Side Scatter, the upper left region corresponding to shrunk erythrocytes with lower volume and higher density. Bottom boxes: Annexin V labeling; the lower right quadrant represents Annexin V-labeled (phosphatidylserine exposing) erythrocytes. At least 5000 erythrocytes were analyzed in each experimental condition 
A

Untreated

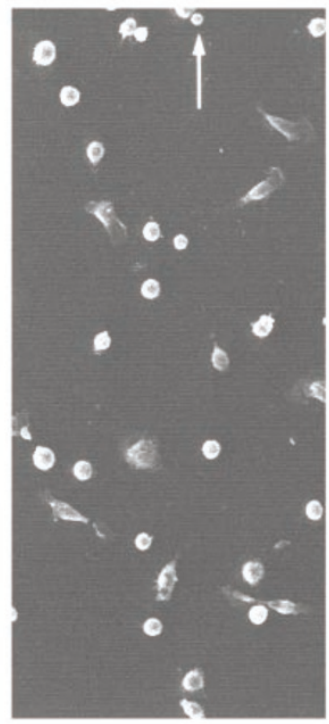

A 23187

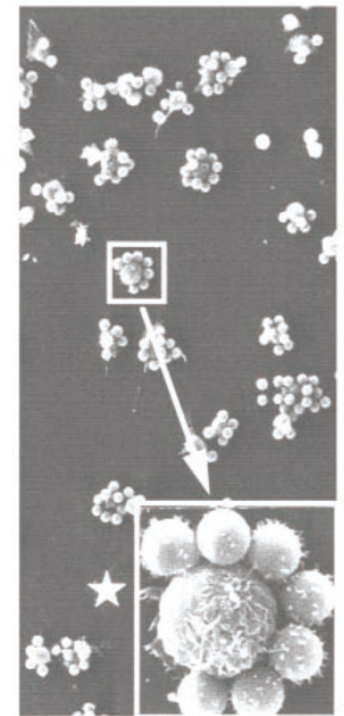

A 23187 + Leupeptin + Ac-DEVD-CHO

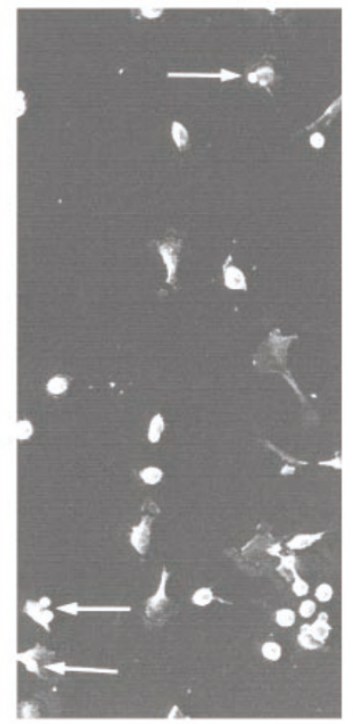

B

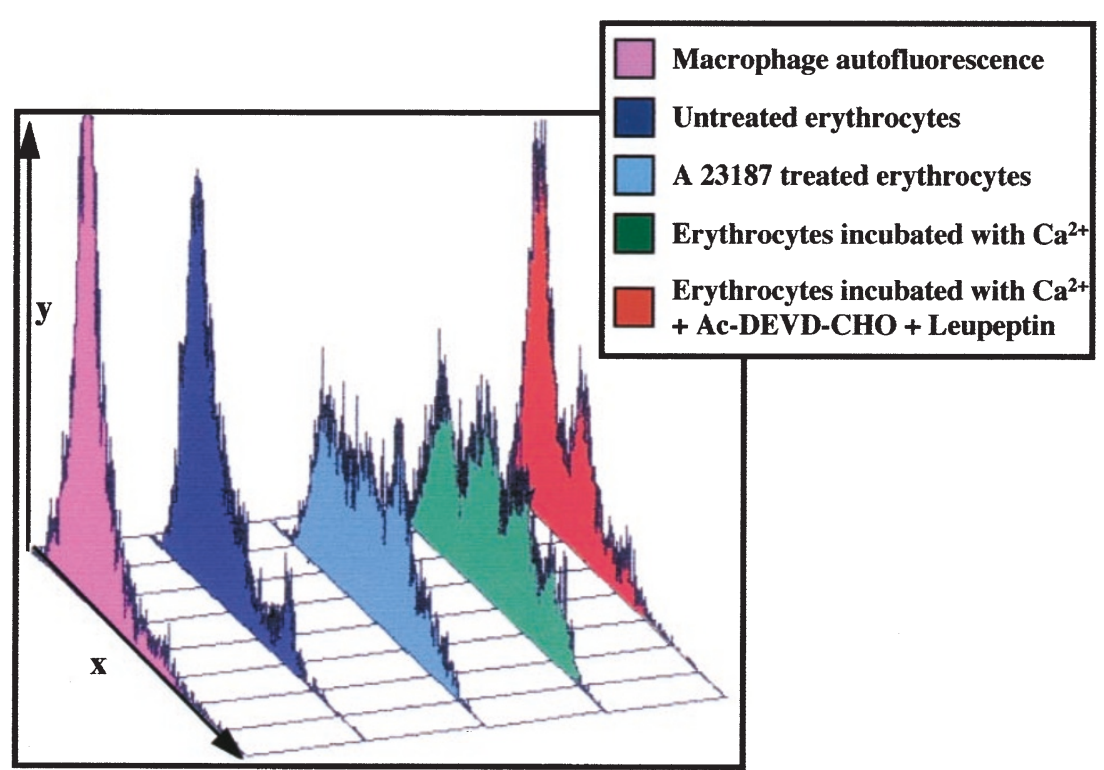

Figure 2 Preventive effect of cystein proteinase inhibitors on the capture and ingestion of human mature erythrocytes by macrophages. (A) Scanning electron microscopy analysis of erythrocyte capture by macrophages. Murine peritoneal macrophages were incubated for 20 min with freshly isolated and purified human mature erythrocytes that had been preincubated either for $48 \mathrm{~h}$ with medium alone, in the absence of $\mathrm{Ca}^{2+}(\mathrm{Untreated})$; or for $3 \mathrm{~h}$ with $\mathrm{A} 23187$ and $\mathrm{Ca}{ }^{2+}$ in the absence (A 23187) or presence (A 23187+Leupeptin+Ac-DEVD-CHO) of pretreatment for 30 min with a mixture of Ac-DEVD-CHO and leupeptin. Arrows in Untreated and in A 23187+Leupeptin+Ac-DEVD-CHO designate macrophages having captured one or two erythrocytes. The star in A 23187 designates a close-up picture of one of the erythrocyte-rosetted macrophages. (B) Flow cytometry analysis of the ingestion of erythrocytes by macrophages. Murine peritoneal macrophages were incubated for $2 \mathrm{~h}$ with either medium alone (Macrophage autofluorescence), or with freshly isolated and purified human mature erythrocytes that had been labeled with $\mathrm{PKH}-26$ after preincubation either for $48 \mathrm{~h}$ with medium alone, in the absence of $\mathrm{Ca}^{2+}$ (Untreated erythrocytes); for $3 \mathrm{~h}$ with $\mathrm{A} 23187$ and $\mathrm{Ca}{ }^{2+}$ (A 23187 treated erythrocytes), or for $48 \mathrm{~h}$ with $\mathrm{Ca}^{2+}$ in the absence (Erythrocytes incubated with $\mathrm{Ca}^{2+}$ ) or presence (Erythrocytes incubated with Ca ${ }^{2+}+\mathrm{Ac}-\mathrm{DEVD}$ $\mathrm{CHO}+$ Leupeptin) of pretreatment for $30 \mathrm{~min}$ with a mixture of Ac-DEVD-CHO and leupeptin. The $x$ axes indicate the mean PKH-26 fluorescence intensity, on a logarithmic scale; the $y$ axes indicate the number of macrophages 


\section{Untreated}
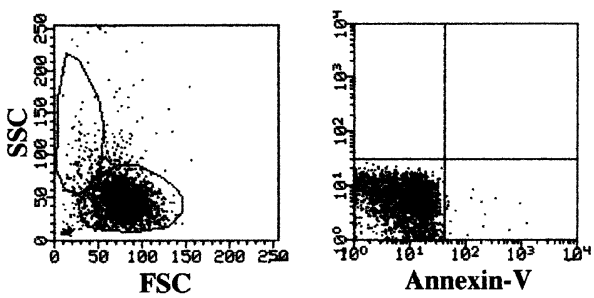

A 23187
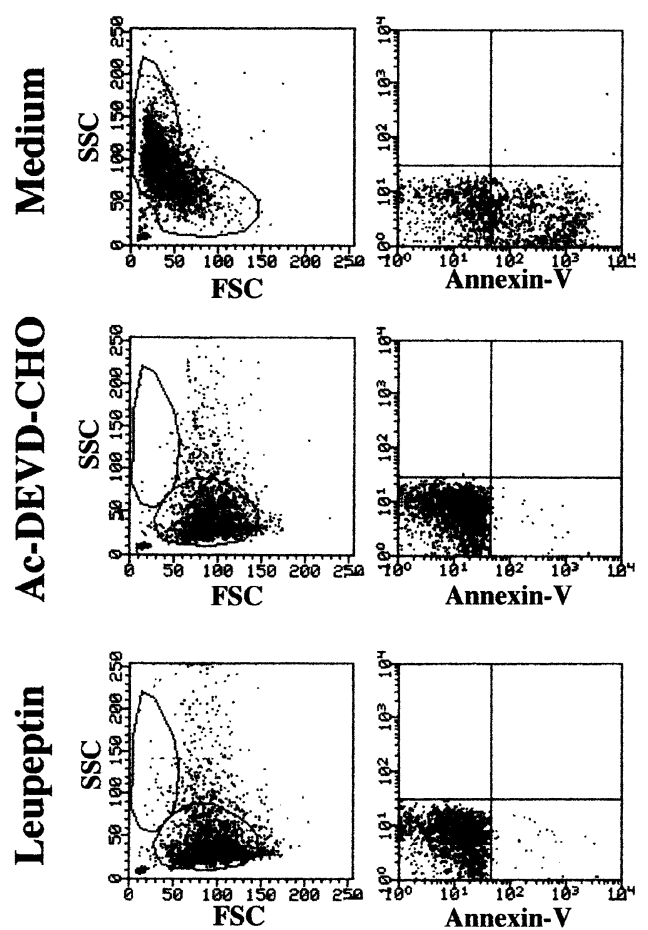

\section{Calcium}
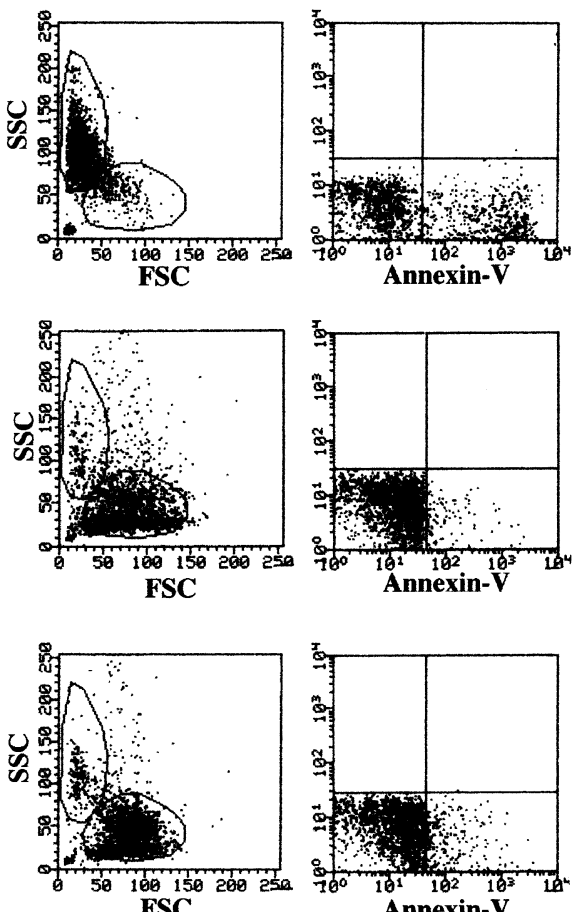

Figure 3 Flow cytometry analysis of the preventive effect of cystein proteinase inhibitors on calcium ionophore- and calcium-induced human mature erythrocyte shape changes and phosphatidylserine exposure. Freshly isolated and purified human mature erythrocytes were analyzed after incubation either for $48 \mathrm{~h}$ in medium alone, in the absence of $\mathrm{Ca}^{2+}$ (Untreated), or for $3 \mathrm{~h}$ with $\mathrm{A} 23187$ and $\mathrm{Ca}^{2+}$ (A 23187), or for $48 \mathrm{~h}$ with $\mathrm{Ca}^{2+}$ (Calcium) in the absence (Medium) or presence of pretreatment for 30 min with Ac-DEVD-CHO or Leupeptin. In each condition, erythrocyte shape (left box) and Annexin V-labeling (right box) were analyzed as in Figure $1 \mathrm{C}$. At least 5000 erythrocytes were analyzed in each experimental condition

directed against these proteins. As a positive control, equivalent amounts of cytoplasmic extracts from the nucleated human Jurkat T-cell line were explored. We detected no cytochrome $c$ in extracts from freshly purified erythrocytes, strongly suggesting that erythrocytes do not have the ability to form a functional apoptosome. The absence of detectable cytochrome $c$ also confirmed the lack of significant contamination of the purified erythrocyte preparations by other cells that contain mitochondria and cytochrome $c$, such as nucleated cells or blood platelets.

As shown in Figure 6A, we identified the uncleaved proform of caspase $3(32 \mathrm{kD})$ in extracts from freshly purified erythrocytes. However, the caspase 3 proform remained unprocessed in extracts of dying erythrocytes that had been treated for $24 \mathrm{~h}$ with $\mathrm{A} 23187$ and $\mathrm{Ca}^{2+}$. As a positive control, we analyzed Jurkat cells either untreated or after apoptosis induction by antibody-mediated engagement of the CD95 death receptor, ${ }^{8}$ using an agonistic antiCD95 antibody $(1 \mu \mathrm{g} / \mathrm{ml})$. As shown in Figure $6 \mathrm{~A}$, caspase 3 was present as an uncleaved proform of $32 \mathrm{kD}$ in cytoplasmic extracts from untreated Jurkat cells, and was processed into the active 20,21 and $17 \mathrm{kD}$ forms ${ }^{29,30}$ in cytoplasmic extracts from apoptotic Jurkat cells.

During apoptosis of nucleated cells, the various pathways of caspase activation always converge on caspase 3 processing and activation. ${ }^{1,4,29,30}$ Therefore, our finding of a lack of caspase 3 processing strongly suggested that erythrocyte death proceeded in the absence of caspase activation. It also indicated that Ac-DEVD-CHO did not prevent erythrocyte death by inhibiting caspase 3 , and 
implied that its preventive effect was due to the inhibition of another proteinase.

In nucleated cells, apoptosis is associated with the caspase-mediated activation of effectors that induce nuclear chromatin damage., ${ }^{1,29}$ Accordingly, cytoplasmic extracts from apoptotic cells induce nuclear features of apoptosis when they are incubated with intact nuclei in cell free assays. ${ }^{30,34,35}$ Using a cell free assay, we incubated cytoplasmic extracts from untreated- or CD95 antibodytreated Jurkat cells, and extracts from untreated- or A 23187 and $\mathrm{Ca}^{2+}$-treated erythrocytes with isolated nuclei. While cytoplasmic extracts from CD95 antibody-treated Jurkat cells induced typical nuclear chromatin condensation and fragmentation in the isolated nuclei, extracts from $A$ 23187 and $\mathrm{Ca}^{2+}$-treated erythrocytes induced no detectable damage in isolated nuclei (Figure 6B).

Table 2 Preventive effect of cysteine proteinase inhibitors on human mature erythrocyte phosphatidylserine (PS) exposure induced by calcium ionophore or by incubation with calcium alone

\begin{tabular}{lcc}
\hline & $\begin{array}{c}\% \\
\text { Inhibition of PS exposure } \\
\text { induced by: }\end{array}$ \\
Inhibitors & A 23187 & $\mathbf{C a}^{2+}$ alone \\
\hline Ac-DEVD-CHO & $90 \pm 6$ & $83 \pm 12$ \\
Leupeptin & $83 \pm 13$ & $89 \pm 8$ \\
Leupeptin+Ac-DEVD-CHO & $94 \pm 2$ & $96 \pm 2$ \\
Tosyl-Lys-cmk & $<2$ & $<2$ \\
\hline
\end{tabular}

Erythrocytes were incubated for $3 \mathrm{~h}$ with $\mathrm{A} 23187$ and $\mathrm{Ca}^{2+}$ or for $48 \mathrm{~h}$ with $\mathrm{Ca}^{2+}$ alone, in the absence or presence of pretreatment for 30 min with AcDEVD-CHO, leupeptin or a mixture of both, or with the serine proteinase inhibitor Tosyl-Lys-cmk. PS exposure was analyzed by flow cytometry, as shown in Figures 1 and 3 . Results represent mean \pm S.D. of five different experiments
Finally, we wondered whether the absence of detectable nuclear effector activity in dying erythrocytes may be due to the presence, in erythrocyte extracts, of putative inhibitors of nuclear degradation. When extracts from $A$ 23187 and $\mathrm{Ca}^{2+}$-treated erythrocytes were mixed $(1: 1)$ with cytoplasmic extracts from CD95 antibody-treated Jurkat cells, no inhibition of nuclear degradation was observed (data not shown). Together, these data suggested that erythrocyte death proceeds in the absence of effectors allowing the induction of the nuclear features of apoptosis, a finding consistent with the absence of detectable caspase 3 activation in dying erythrocytes.

\section{Discussion}

Mitochondria have been proposed to play a central role in programmed cell death (PCD), ${ }^{5-7,9,10}$ through the release of pro-apoptotic factors that induce either caspase-dependent or caspase-independent executionary pathways. Until now, however, PCD has only been investigated in cells that contain mitochondria.

Human mature erythrocytes are terminally differentiated cells of the erythroid lineage, that are devoid of mitochondria, as well as of nucleus and other organelles, and have a normal life span of 120 days that is ended by a process of senescence leading to their clearance from the peripheral blood by reticuloendothelial cells. Mature erythrocytes have been considered as the sole human cell type unable to undergo PCD, due to their lack of mitochondria and nucleus, and to the finding that they survive two conditions that induce PCD in vitro in all nucleated human cells tested so far, i.e. treatment with the protein kinase inhibitor

\section{Untreated}

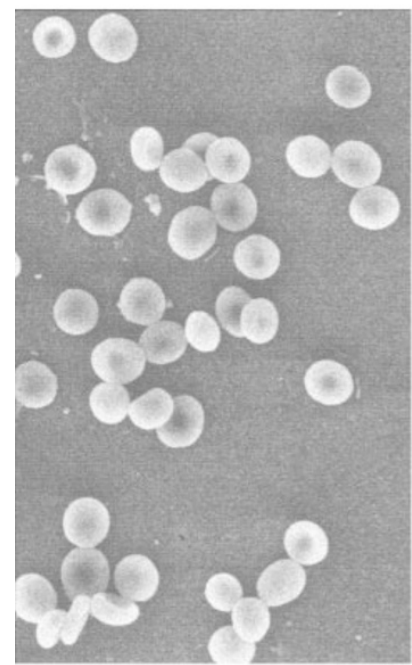

\section{Calcium}

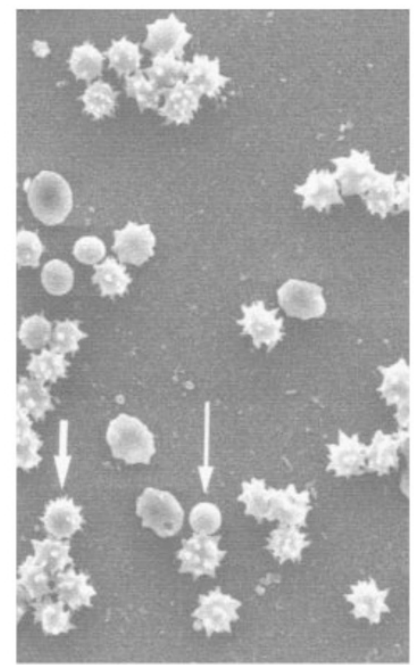

\section{Calcium + Ac-DEVD-CHO}

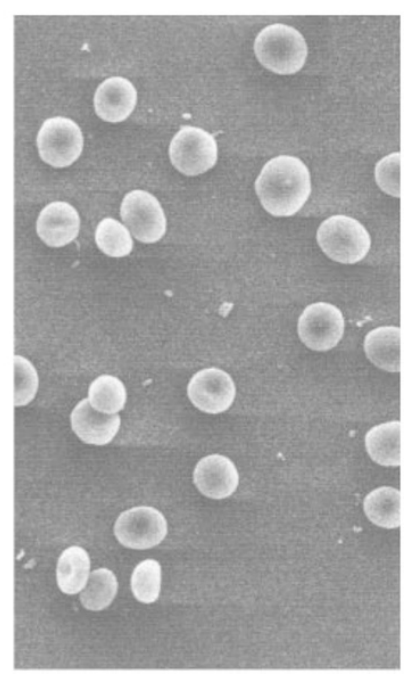

Figure 4 Scanning electron microscopy analysis of the preventive effect of cystein proteinase inhibitors on calcium-induced human mature erythrocyte morphological changes. Freshly isolated and purified human mature erythrocytes were incubated for $48 \mathrm{~h}$ either in medium alone, in the absence of $\mathrm{Ca}^{2+}$ (Untreated), or with $\mathrm{Ca}^{2+}$ in the absence (Calcium) or presence (Calcium+Ac-DEVD-CHO) of pretreatment for 30 min with Ac-DEVD-CHO. The short arrow shows a spheroechinocyte with spicules, and the long arrow a smooth spherocyte 
Table 3 Preventive effect of cysteine proteinase inhibitors on the macrophage capture and phagocytosis of calcium ionophore-treated human mature erythrocytes

\begin{tabular}{|c|c|c|c|}
\hline \multirow[b]{2}{*}{ Human erythrocytes } & \multicolumn{2}{|c|}{ Capture } & \multirow[b]{2}{*}{$\begin{array}{l}\text { Phagocytosis } \\
\text { Inhibition \% }\end{array}$} \\
\hline & $\begin{array}{c}\text { Numbers of captured } \\
\text { erythrocytes }\end{array}$ & Inhibition \% & \\
\hline $\begin{array}{l}\text { Untreated } \\
\text { lonophore A } 23187 \text { treated }\end{array}$ & 6 & - & - \\
\hline $\begin{array}{l}\text { In the absence of inhibitor } \\
\text { In the presence of inhibitors }\end{array}$ & 550 & - & - \\
\hline Ac-DEVD-CHO & 70 & 87 & 60 \\
\hline Leupeptin & 25 & 95 & 49 \\
\hline Leupeptin+Ac-DEVD-CHO & 14 & 97 & 95 \\
\hline
\end{tabular}

Erythrocytes were incubated for $3 \mathrm{~h}$ with $\mathrm{A} 23187$ and $\mathrm{Ca}^{2+}$ in the absence or presence of pretreatment for 30 min with Ac-DEVD-CHO, leupeptin or a mixture of both. After washing, erythrocytes were then incubated for 20 min (capture), or labeled with PKH-26 and incubated for $2 \mathrm{~h}$ (phagocytosis) with murine peritoneal macrophages. Capture was assessed by scanning electron microscopy and phagocytosis by flow cytometry analysis (as shown in Figure 2). Results presented are from one representative experiment out of three

Table 4 Preventive effect of cysteine proteinase inhibitors on phosphatidylserine (PS) exposure and subsequent in vivo clearance of murine erythrocytes induced by in vitro treatment with calcium

\begin{tabular}{|c|c|c|c|c|c|}
\hline \multirow[b]{2}{*}{ Murine erythrocytes } & \multirow{2}{*}{$\begin{array}{l}\text { Percentage of erythrocytes } \\
\text { expressing PS in vitro* }\end{array}$} & \multicolumn{4}{|c|}{$\begin{array}{l}\text { Number of PKH-26-labeled erythrocytes remaining in the circulation at } \\
\text { different time points after injection }{ }^{\star *}\end{array}$} \\
\hline & & $+1 \mathrm{~h}$ & $+6 h$ & $+20 h$ & $+48 h$ \\
\hline $\begin{array}{l}\text { Untreated } \\
\text { Incubated with } \mathrm{Ca}^{2+} \text { for } 4 \text { days }\end{array}$ & 1 & 364 & 343 & 317 & 305 \\
\hline $\begin{array}{l}\text { In the absence of inhibitor } \\
\text { In the presence of inhibitor }\end{array}$ & 84 & 34 & 11 & 11 & 10 \\
\hline $\begin{array}{l}\text { Ac-DEVD-CHO } \\
\text { Leupeptin } \\
\text { Leupeptin+Ac-DEVD-CHO }\end{array}$ & $\begin{array}{l}9 \\
8 \\
4\end{array}$ & $\begin{array}{l}276 \\
219 \\
293\end{array}$ & $\begin{array}{l}260 \\
230 \\
247\end{array}$ & $\begin{array}{l}220 \\
250 \\
284\end{array}$ & $\begin{array}{l}210 \\
230 \\
292\end{array}$ \\
\hline
\end{tabular}

*Flow cytometry analysis of annexin-V labeling was performed as in Figures 1 and 3, prior to erythrocyte PKH-26 labeling and injection in recipient mice. **Erythrocyte PKH-26 labeling, injection in recipient mice, and subsequent flow cytometry analysis were performed as in Figure 5, in three additional recipient mice. Results are from one representative recipient mouse

a

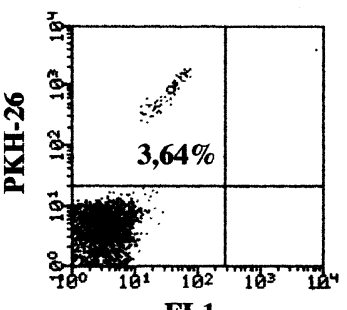

FL1

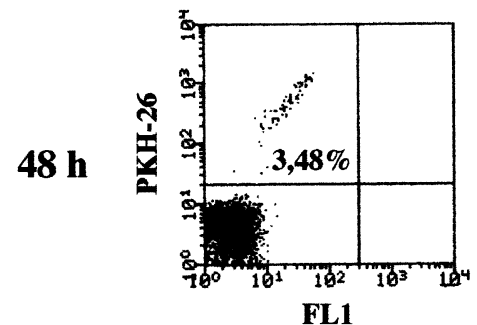

b

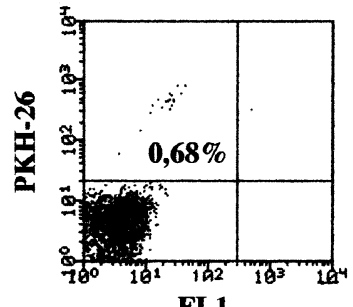

FL1

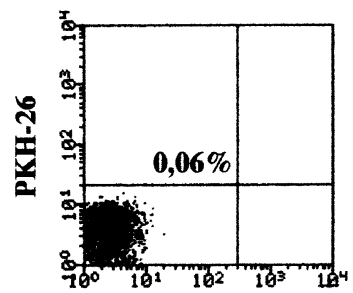

FL1

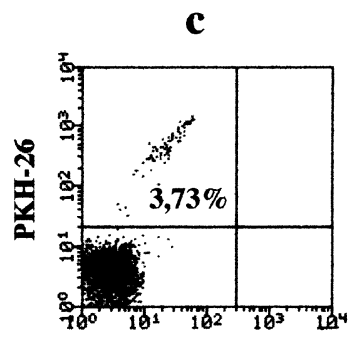

FL1

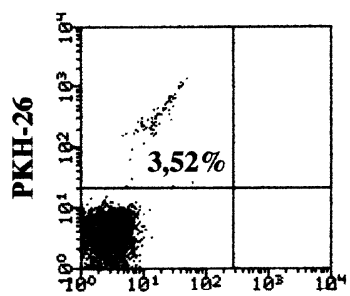

FL1

Figure 5 In vitro treatment of murine mature erythrocytes with calcium and cystein proteinase inhibitors prevents their subsequent in vivo clearance from the circulation. Freshly isolated and purified murine erythrocytes were labeled with PKH-26 and injected intravenously in syngeneic recipient mice either immediately after their isolation (A) or after incubation for 4 days at $20^{\circ} \mathrm{C}$ with $\mathrm{Ca}^{2+}$ in the absence (B) or presence (C) of pretreatment for 30 min with a mixture of Ac-DEVD$\mathrm{CHO}$ and leupeptin. Flow cytometry analysis of the peripheral blood of the recipient mice was then performed $1 \mathrm{~h}(1 \mathrm{~h})$ or $48 \mathrm{~h}(48 \mathrm{~h})$ after injection. Upper left quadrant: PKH-26 labeled erythrocytes retrieved from the circulation (numbers indicate their percentages). At least 10000 erythrocytes were analyzed in each experimental condition. Results shown are from one representative recipient mouse out of the three used in this experiment 


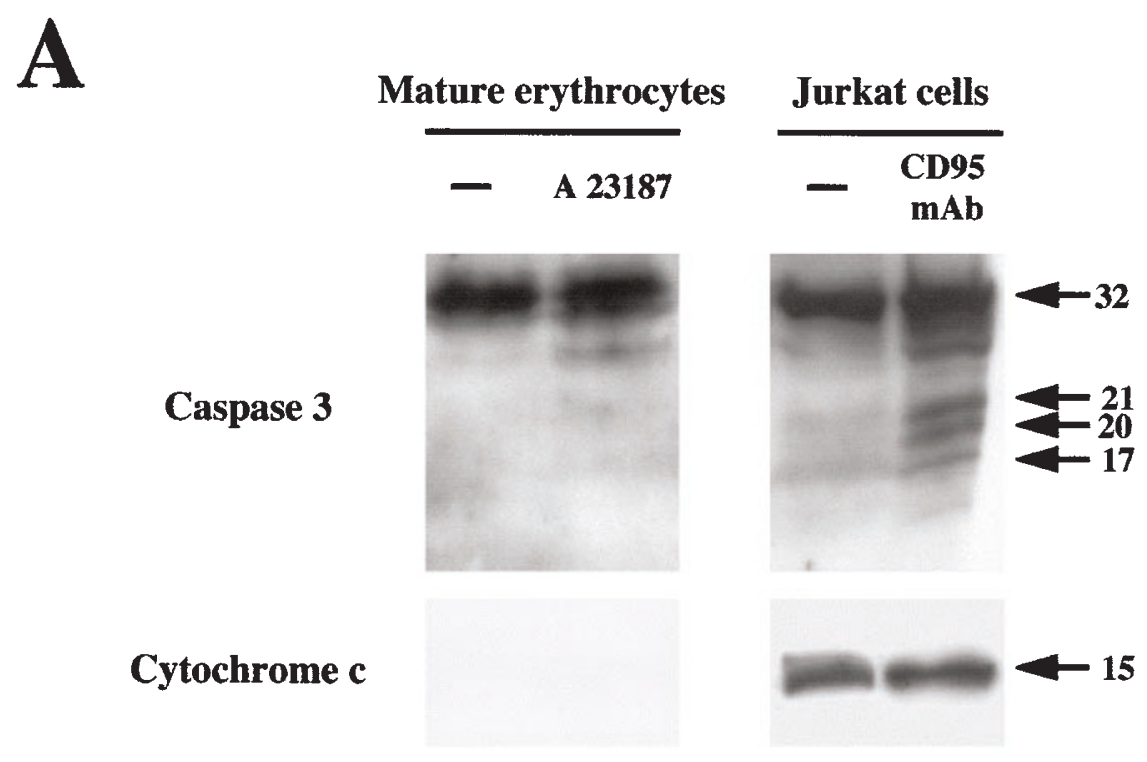

B
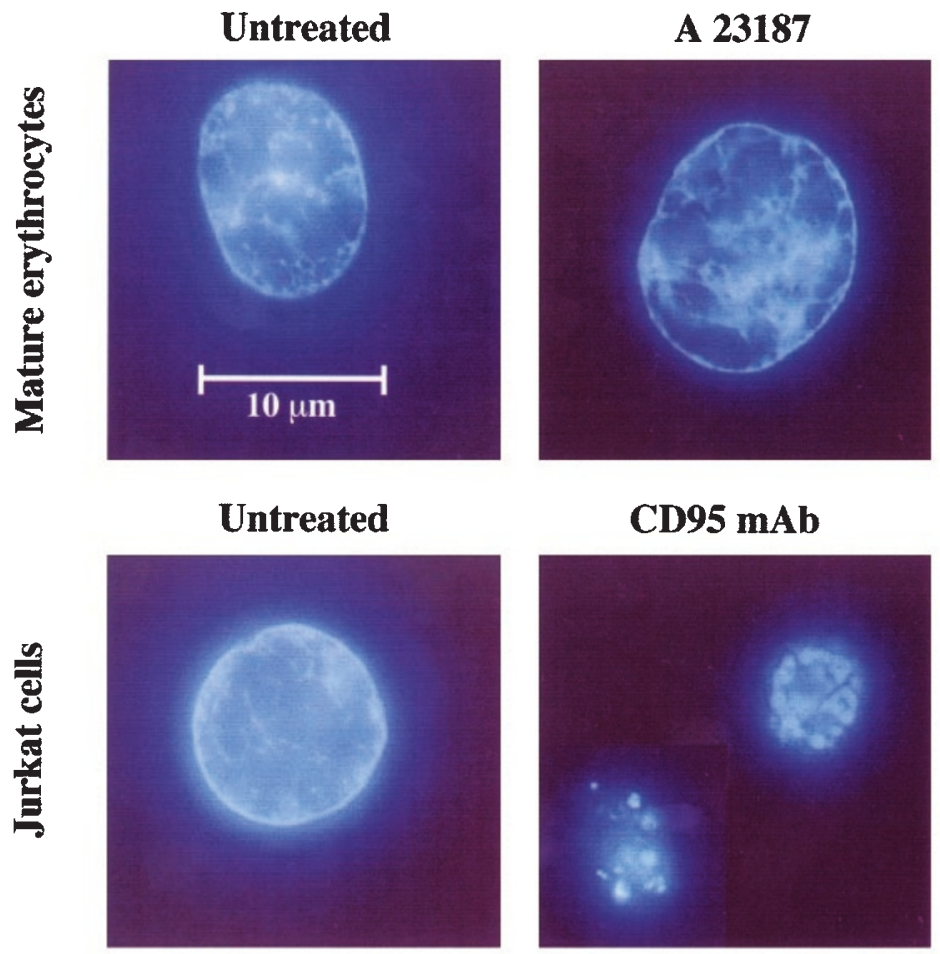

Figure 6 Lack of cytochrome $c$ in human mature erythrocytes, and of both detectable caspase 3 activation and cytoplasmic effectors of nuclear apoptosis during calcium ionophore-induced erythrocyte death. (A) Western blotting. Extracts from freshly isolated and purified human mature erythrocytes that had been incubated for $24 \mathrm{~h}$ either in medium alone, in the absence of $\mathrm{Ca}^{2+}$ (-) or with $\mathrm{A} 23187$ and $\mathrm{Ca}^{2+}$ (A 23187), were subjected to Western blotting with antibodies specific for human caspase 3 or human cytochrome $c$. As a positive control, Western blotting was performed on cytoplasmic extracts from Jurkat T cells that had been incubated for $6 \mathrm{~h}$ in medium alone (-), or with an agonistic mAb specific for the CD95 death receptor (CD95 mAb). (B) Cell free assays of nuclear apoptosis. Isolated human nuclei were incubated for $2 \mathrm{~h}$ with cytoplasmic extracts from human mature erythrocytes (Mature erythrocytes) that had been incubated for $24 \mathrm{~h}$ with either medium alone, in the absence of $\mathrm{Ca}^{2+}$ (Untreated), or with $\mathrm{A} 23187$ and $\mathrm{Ca}^{2+}$ (A 23187). As a positive control, isolated human nuclei were incubated for $2 \mathrm{~h}$ with cytoplasmic extracts from human Jurkat T cells (Jurkat cells) that had been incubated for $6 \mathrm{~h}$ with either medium alone (Untreated) or with the agonistic anti-CD95 antibody (CD95 mAb). Nuclei were visualized by fluorescent microscopy after staining with Hoechst 33 342. Results shown in $\mathbf{A}$ and $\mathbf{B}$ are representative of three independent experiments 
staurosporine, and culture in the absence of serum and of other survival factors. ${ }^{14}$

While confirming that mature erythrocytes survive staurosporine treatment and culture in the absence of serum, our findings indicate that they constitutively express death effectors allowing them to undergo a rapid process of selfdestruction that shares several features with apoptosis, including cell shrinkage, plasma membrane microvesiculation, phosphatidylserine externalization, and leading to erythrocyte disintegration, or, in the presence of macrophages, to macrophage ingestion of the dying erythrocytes. This regulated form of PCD was induced by $\mathrm{Ca}^{2+}$ influx, and prevented by in vitro treatment with cysteine proteinase inhibitors, that allowed human mature erythrocytes to survive in vitro, and murine mature erythrocytes to survive in vivo. Independently of their potential implication for the control of mature erythrocyte survival and death, our findings provide the first identification, to our knowledge, that a death program can operate in the absence of mitochondria.

The most likely candidates for a cysteine proteinasedependent process of PCD with an apoptosis-like phenotype are caspases. ${ }^{1,4,29,30}$ Among the two cysteine proteinases inhibitors that prevented $\mathrm{Ca}^{2+}$-induced erythrocyte death, Ac-DEVD-CHO has been previously described as a selective inhibitor of caspase 3 , one of the main effector caspases involved in apoptosis induction. 1,4,29,30 Our results, however, indicate that caspase 3 is not involved in erythrocyte death. Caspases are synthesized as zymogens that require to be cleaved in order to be activated. While we identified the proform of caspase 3 in erythrocytes, it was not processed during erythrocyte death.

Using a cell free assay, in which erythrocyte extracts were incubated with isolated nuclei, we found that $\mathrm{Ca}^{2+}$. induced erythrocyte death did not lead to the activation of effectors of nuclear apoptosis. This further suggested the absence of activated effector caspases, since they have been shown, in cell-free assays, to induce nuclear membrane lamin cleavage, and to activate effectors of chromatin and DNA damage that are present as inactive proforms in the nucleus, such as caspase-activated Dnase (CAD) and acinus. ${ }^{30,34,35}$

Thus, while the presence-and potential activation-of other caspase proforms in erythrocytes remain to be assessed, our findings strongly suggest that $\mathrm{Ca}^{2+}$-induced erythrocyte death proceeds in the absence of caspase activation, and does not lead to the activation of effectors of the nuclear features of apoptosis.

Our findings that caspase 3 was not processed during erythrocyte death indicated that Ac-DEVD-CHO did not exert its preventive effect by inhibiting the activity of caspase 3 . Therefore, the most likely explanation, at this stage, for the preventive effect of both leupeptin and AcDEVD-CHO is that they acted by inhibiting a cysteine protease target other than a caspase. The major $\mathrm{Ca}^{2+}$ activated cysteine protease present in erythrocytes is calpain. ${ }^{33}$ Calpain has been reported to be involved in apoptosis of nucleated cells, ${ }^{31,32}$ and in a form of apoptosis-like death process of an anucleated cell type, the blood platelet. ${ }^{17}$ While blood platelets are cells that contain mitochondria, this death process showed several similarities with the erythrocyte death process that we described here. Indeed, apoptosis-like blood platelet death was induced by $\mathrm{Ca}^{2+}$ influx, did not depend on caspase activation and appeared not to depend on mitochondrial membrane permeabilization, since it occurred in the absence of cytochrome $c$ release. The phenotype of cell death was prevented in part by a calpain inhibitor, calpeptin, as well as by the broad caspase inhibitor zVAD-fmk, that has been previously described as specific for caspases, but was shown in this study to also inhibit calpain in an in vitro assay. ${ }^{17}$ There is, however, at least one difference between this platelet death process and the erythrocyte death process that we identified. Indeed, cysteine proteinase inhibitors (calpeptin and z-VAD-fmk), while attenuating platelet microvesiculation, did neither prevent platelet shrinkage nor phosphatidylserine externalization. ${ }^{17}$ Although the inhibitors we used were not the same, we observed a preventive effect on cell death and on all apoptosis-like features in erythrocytes, i.e. cell shrinkage, microvesiculation, phosphatidylserine externalization, erythrocyte disintegration, and, in the presence of macrophages, macrophage ingestion of erythrocytes. Thus, whether the same effector mechanisms, including calpain activation, account for both platelet and erythrocyte apoptosis-like death, remains to be assessed.

Mature erythrocytes represent the end stage of the erythroid lineage emerging from erythroid progenitors through a complex process of differentiation that involves the physiological loss of their nucleus, mitochondria and other organelles. Recent findings indicate that terminal differentiation into mature erythrocytes is preceded by a form of abortive apoptosis induction, that involves transient caspase activation. ${ }^{36}$ Is the apparently peculiar death program operating in mature erythrocytes a consequence of their particular process of terminal differentiation? Or is it a legacy of cryptic effectors of cytoplasmic apoptosis that are already present in their erythroid progenitors? Identification of the molecular mechanisms of self-destruction in mature erythrocytes should allow one to assess to what extent the death effectors involved may be components of the various independent death programs that have been recently suggested to exist in parallel in nucleated mammalian cells, ${ }^{37,38}$ and whose multiplicity may be related to the ancient evolutionary origins of PCD. ${ }^{38-40}$

While we did not identify the death effectors operating in mature erythrocytes, our findings that inhibitors of cysteine proteinases are able to prevent $\mathrm{Ca}^{2+}$-induced erythrocyte death both in vitro and in vivo has implications for therapeutic modulation of erythrocyte survival. Firstly, blood transfusion may benefit from treatments able to inhibit premature erythrocyte death in vitro. Secondly, shortened survival and accelerated clearance of erythrocytes from the blood circulation occur in several diseases. ${ }^{19}$ Provided that accelerated erythrocyte clearance in such diseases depend on a process of $\mathrm{Ca}^{2+}$-dependent PCD similar to that we have evidenced, our findings suggest the possibility that cysteine proteinase inhibitors might allow the in vivo prevention of premature erythrocyte death. Thirdly, senescence is the physiological process that ends the normal erythrocyte life span of 120 days. Erythrocyte senescence is 
associated with progressive $\mathrm{Ca}^{2+}$ influx, ${ }^{24,25}$ and with most, if not all, of the apoptosis-like features that characterize the rapid $\mathrm{Ca}^{2+}$-induced premature erythrocyte death process that we identified here. If senescence represents the timedependent induction of the same self-destruction process, it is possible that the normal life span of erythrocytes might be extended through therapeutic intervention.

Finally, our findings suggest the interesting possibility that there are physiological survival factors, present in vivo, that act by preventing or delaying $\mathrm{Ca}^{2+}$-induced death of mature erythrocytes. Indeed, while mature erythrocyte life span is 120 days in vivo, incubation in vitro with a physiological concentration $(2.5 \mathrm{mM})$ of $\mathrm{Ca}^{2+}$, identical to that present in the peripheral blood, was sufficient to induce premature erythrocyte death within 6 days. It has been previously proposed that the survival of all nucleated mammalian cells depends on the constant repression of their self-destruction program by signals provided by other cells. ${ }^{2,13,14,27}$ Our findings suggest that this may also the case for mature erythrocytes, but that signals provided by other cells would only be required for erythrocyte survival when erythrocytes are in the presence of $\mathrm{Ca}^{2+}$.

In summary, the findings presented here indicate that mature erythrocytes share, with all other mammalian cell types, the capacity to self-destruct in response to environmental changes. They suggest that erythrocytes may represent a useful model for the identification of effectors of PCD and senescence that are able to operate in a minimal cell devoid of nucleus, mitochondria and other organelles. They also indicate that death and survival of mature erythrocytes, as death and survival of all other mammalian cells, may be modulated by physiological regulation, pathological dysregulation, and therapeutic intervention.

\section{Materials and Methods}

\section{Cells and culture conditions}

Human erythrocytes were purified, as previously described, ${ }^{23,41}$ from heparinized peripheral blood from healthy donors ( $\mathrm{Rh}+$ blood type), supplied by the Etablissement Régional de Transfusion Sanguine de Lille. After blood sedimentation by centrifugation $\left(2000 \times g, 4^{\circ} \mathrm{C}\right.$, $5 \mathrm{~min}$ ), plasma, platelets and leukocytes were removed by pipetting, and erythrocytes were washed three times in Dulbecco's phosphatebuffered saline solution pH 7.4 (PBS: $137 \mathrm{mM} \mathrm{NaCl}, 2.7 \mathrm{mM} \mathrm{KCl}$, $8.1 \mathrm{mM} \mathrm{Na}_{2} \mathrm{HPO}_{4}$ and $\left.1.5 \mathrm{mM} \mathrm{KH}_{2} \mathrm{PO}_{4}\right)$, and resuspended $\left(10^{7} / \mathrm{ml}\right)$ in HEPES buffer ( $10 \mathrm{mM}$ HEPES, $140 \mathrm{mM} \mathrm{NaCl}$ ), pH 7.4 supplemented with $0.1 \%$ human serumalbumin (SIGMA Chemicals, St-Louis, MO, USA) in the absence or presence of $\mathrm{Ca}^{2+}\left(2.5 \mathrm{mM} \mathrm{CaCl}_{2}\right)$ and other reagents (as indicated), and incubated at $37^{\circ} \mathrm{C}$ under $5 \% \mathrm{CO}_{2}$ atmosphere. Murine erythrocytes were purified from heparinized peripheral blood of 6-8-week-old Balb-C female mice (IFFA CREDO, L'Arbreles, France), using the same procedures as described above for human erythrocytes. Murine erythrocytes $\left(10^{7} / \mathrm{ml}\right)$ were resuspended in HEPES buffer $\mathrm{pH} 7.4$, in the absence or presence of $\mathrm{Ca}^{2+}$ (2.5 $\mathrm{mM} \mathrm{CaCl}_{2}$ ) and other reagents (as indicated). Human Jurkat cells were cultured at $37^{\circ} \mathrm{C}$ under $5 \% \mathrm{CO}_{2}$ atmosphere in RPMI 1640 (Gibco/BRL, Gaithersburg, MD, USA) supplemented with $10 \%$ heatinactivated serum (Summit Biotechnology, Greeley, CO, USA), $2 \mathrm{mM}$ L-glutamine, $1 \mathrm{mM}$ sodium pyruvate, $100 \mathrm{U} / \mathrm{ml}$ penicillin and $100 \mathrm{mg} /$ $\mathrm{ml}$ streptomycin (Gibco). When so indicated, Jurkat cells $\left(10^{6} / \mathrm{ml}\right)$ were incubated for $6 \mathrm{~h}$ in the absence or presence of the agonistic antihuman CD95 IgM monoclonal antibody (mAb) CH11 (1 $\mu \mathrm{g} / \mathrm{ml}$ ) (Coulter Corporation, Fullerton, CA, USA).

\section{Reagents}

The $\mathrm{Ca}^{2+}$ ionophore A 23187 from Streptomyces chartreusis was purchased from Calbiochem (La Jolla, CA, USA), the protein kinase inhibitor staurosporine (from Streptomyces) from SIGMA (St-Louis, MO, USA), the caspase 3 inhibitor Ac-Asp-Glu-Val-L-Asp-aldehyde (Ac-DEVD-CHO), the calpain/cysteine proteinase inhibitor Ac-LeuLeu-Arg-CHO (leupeptin) and the serine proteinase inhibitor tosyl-Lyschloromethylketone (tos-Lys-cmk chloride) from BACHEM (Voisins-leBretonneux, France). The fluorescein isothiocyanate (FITC)-conjugated annexin $\mathrm{V}$ from $\mathrm{R}$ D Systems (Abington, UK) and PharMingen (San Diego, CA, USA), the lipophilic fluorescent probe PKH-26 from SIGMA, the anti-human caspase-3 polyclonal antibody, and the antihuman cytochrome $\mathrm{c} \mathrm{mAb}(7 \mathrm{H} 8.2 \mathrm{C} 12)$ were from PharMingen. The total hemoglobin kit 525-A allowing quantification of extracellular release of hemoglobin (hemolysis) was from SIGMA.

\section{Flow cytometry analysis}

Flow cytometry analysis was performed on a FACScan flow cytometer (Becton Dickinson, San Jose, CA, USA), using the LYSIS software for acquisition and analysis. The light-scatter channels were set on linear gains and the fluorescence channels on a logarithmic scale, a minimum of 5000 cells being analyzed in each condition. Erythrocyte size and density were assessed using forward and side-angle scatters (FSC versus SSC). For analysis of FITC-annexin V labeling, erythrocytes were washed twice with cold PBS buffer $\mathrm{pH} 7.4$ and resuspended $\left(10^{6}\right.$ cells) in HEPES buffer $\mathrm{pH} 7.4$ containing $2.5 \mathrm{mM}$ calcium for $15 \mathrm{~min}$ at room temperature in the dark with $10 \mu \mathrm{l}(0.1 \mu \mathrm{g})$ of FITC-annexin V solution, and, following washing, cells were gated for biparametric histograms FL1 versus FL2.

The in vitro phagocytosis of purified human mature erythrocytes was measured as previously described. ${ }^{23,41}$ Briefly, erythrocytes, after indicated in vitro pretreatments were labeled with the lipophilic fluorescent probe $\mathrm{PKH}-26$ (acridine orange conjugated to a 26 -carbon atom aliphatic chain), and then incubated $\left(2 \times 10^{7}\right.$ erythrocytes) with murine peritoneal macrophages monolayers in $250 \mu \mathrm{l}$ DMEM medium for $2 \mathrm{~h}$ at $37^{\circ} \mathrm{C}$. The unbound erythrocytes were then removed by three washes with DMEM, and the macrophage-bound, but not internalized, erythrocytes, were lysed by treatment for $5 \mathrm{~min}$ with a hypotonic buffer and removed by washing with DMEM. The adherent macrophages were then detached with a lidocaine solution (SIGMA), washed, and further treated with $70 \%$ ethanol to fix the cells and remove the $\mathrm{PKH}$ 26-labeled erythrocyte membranes still adhering to the macrophages. The extent of phagocytosis was assessed by flow cytometry analysis of the intensity of PKH-26 macrophage fluorescence.

The in vivo clearance of $\mathrm{PKH}-26$-labeled murine erythrocytes was measured as follows. After indicated in vitro treatments, erythrocytes were centrifuged $\left(2000 \times \mathrm{g}, 4^{\circ} \mathrm{C}, 5 \mathrm{~min}\right)$, washed three times with PBS buffer $\mathrm{pH} 7.4$ and labeled with $\mathrm{PKH}-26$, as previously described, ${ }^{23,41}$ followed by three washes in DMEM. After centrifugation, $10^{9}$ erythrocytes were resuspended in $100 \mu$ of PBS buffer $\mathrm{pH} 7.4$ and the suspension was injected in the peripheral blood (retro-orbital sinus) of syngeneic recipient 6 -8-week-old BALB/c female mice after ether anesthesia. At indicated time points, $5-10 \mu$ of peripheral blood were taken by retro-orbital punction after ether anesthesia. The numbers of $\mathrm{PKH}-26$ labeled erythrocytes remaining in the circulation were then assessed by flow cytometry analysis of at least 10000 erythrocytes. 


\section{Scanning electron microscopy}

Erythrocyte morphology was analyzed after indicated in vitro treatments. For analysis of erythrocyte capture by macrophages, erythrocytes, after indicated in vitro pretreatments, were incubated $\left(2 \times 10^{7}\right.$ erythrocytes) with murine peritoneal macrophage monolayers in $250 \mu \mathrm{l}$ DMEM medium for $20 \mathrm{~min}$ at $37^{\circ} \mathrm{C}$, followed by three washes with DMEM to remove unbound erythrocytes. In both cases (erythrocyte morphology and erythrocyte capture by macrophages) cells were directly fixed for $4 \mathrm{~h}$ with a $1.25 \%$ glutaraldehyde solution in $0.1 \mathrm{M}$ sodium cacodylate buffer $\mathrm{pH} 7.2$ and post-fixed for $4 \mathrm{~h}$ in $1 \%$ osmium tetraoxide in the same buffer. The suspensions were then filtered onto $0.2 \mu$ Anodisc filters and dehydrated in an ethanol series. After drying with carbon dioxide by the critical point method and sputter-coating with gold, samples were examined on a 35 CF JEOL scanning electron microscope.

\section{Western blotting}

After indicated in vitro treatments, human erythrocytes $\left(10^{8}\right.$ cells) or human Jurkat T cells $\left(5 \times 10^{6}\right.$ cells) were diluted in PBS, lysed by three freeze/thaw cycles, centrifuged at $14000 \times \mathrm{g}$ for $30 \mathrm{~min}$ at $4^{\circ} \mathrm{C}$. The cytosolic extracts were diluted in lysis buffer (1\% NP-40, $50 \mathrm{mM}$ Tris pH 8.0, $150 \mathrm{mM} \mathrm{NaCl}, 5 \mathrm{mM}$ EDTA, $6 \mathrm{mM}$ CHAPS, $10 \mu \mathrm{g} / \mathrm{ml}$ leupeptin, aprotonin, pepstatin A, $1 \mathrm{mM}$ PMSF). Each cytoplasmic extract was then boiled for $5 \mathrm{~min}$ in $2 \times$ Laemmli sample buffer with 2- $\beta \mathrm{ME}$ and run on a 4/ $20 \%$ polyacrylamide gel (BioRad Laboratories, Hercules, CA, USA). Proteins were then transferred to PVDF membrane (Amersham, Little Chalfont, UK), and immunoblotted with the anti-human caspase 3 or the anti-human cytochrome $c$ antibodies and then visualized using horseradish-peroxydase-conjugated secondary antibodies (Amersham), followed by enhanced chemiluminescence (Amersham).

\section{Cell free assays of nuclear apoptosis}

After indicated in vitro treatments, cytoplasmic extracts were prepared from purified human mature erythrocytes or from Jurkat T cells and were

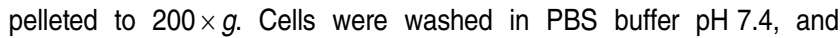
incubated on ice for 20 min with Cell Extract Buffer (CEB) (50 mM PIPES $\mathrm{pH} 7.4,50 \mathrm{mM} \mathrm{NaCl}, 5 \mathrm{mM}$ EGTA, $2 \mathrm{mM} \mathrm{MgCl} 2,1 \mathrm{mM}$ dithiothreitol (DTT), $10 \mu \mathrm{M}$ cytochalasin $\mathrm{B}$ and $1 \mathrm{mM}$ phenylmethylsulfonyl fluoride (PMSF)). Cells were diluted in an equal volume of CEB followed by incubation on ice for $20 \mathrm{~min}$. Cells were lysed by repeated freezing and thawing and centrifuged at $4^{\circ} \mathrm{C}$ for 15 min at $14000 \times g$. The cytosol was removed and immediately frozen at $-80^{\circ} \mathrm{C}$.

Isolated nuclei from human CEM $\mathrm{T}$ cells were prepared as previously described. ${ }^{42}$ Briefly, cells were harvested by centrifugation

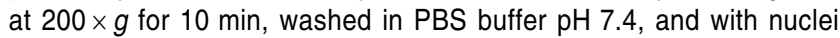
isolation buffer NB (10 mM PIPES pH 7.4, $10 \mathrm{mM} \mathrm{NaCl}, 2 \mathrm{mM} \mathrm{MgCl}$, $1 \mathrm{mM}$ dithiothreitol (DTT), $10 \mu \mathrm{M}$ cytochalasin $\mathrm{B}$ and $1 \mathrm{mM}$ phenylmethylsulfonyl fluoride (PMSF)), and then resuspended in 10 volumes of this buffer. Cells were allowed to swell on ice for $20 \mathrm{~min}$, followed by gentle lysis with a Dounce homogeneizer. Nuclei were then layered over $30 \%$ sucrose in NB buffer and resuspended in nuclei storage buffer (10 mM PIPES pH 7.4, $80 \mathrm{mM} \mathrm{NaCl}, 5 \mathrm{mM}$ EGTA, $250 \mathrm{mM}$ sucrose, $1 \mathrm{mM}$ dithiothreitol (DTT), $0.2 \mathrm{mM}$ spermine, $0.5 \mathrm{mM}$ spermidine, $1 \mathrm{mM}$ phenylmethylsulfonyl fluoride (PMSF) and $50 \%$ glycerol). Nuclei were then stored at $-80^{\circ} \mathrm{C}$.

Cell free reactions $(25 \mu \mathrm{l})$ comprised $20 \mu \mathrm{l}$ of cytoplasmic extracts (20-30 mg/ml protein), $1 \mu \mathrm{l}\left(2 \times 10^{5}\right.$ cells) of isolated nuclei and $4 \mu \mathrm{l}$ of Extract Dilution Buffer (EDB) (10 mM HEPES, $50 \mathrm{mM} \mathrm{NaCl}, 2 \mathrm{mM} \mathrm{MgCl}$, $5 \mathrm{mM}$ EGTA, $1 \mathrm{mM}$ DTT, $2 \mathrm{mM}$ ATP, $10 \mathrm{mM}$ phosphocreatine and $50 \mu \mathrm{g} /$ $\mathrm{ml}$ creatine kinase), as previously described. ${ }^{42}$ The nuclei were stained with Hoechst $33342(10 \mu \mathrm{M})$ (Sigma) and examined by UV fluorescent microscopy, using a Leica DMRB fluorescent microscope.

\section{Acknowledgements}

We all miss André Verbert, who provided a kind interest and support to this project. This work was supported in part by grants from Institut National de la Sante et de la Recherche Medicale (INSERM), Universite Paris 7, Agence Nationale de Recherches sur le Sida (ANRS), Ensemble contre le Sida (ECS), Fondation pour la Recherche Medicale (FRM), Etablissement français des greffes (to JC Ameisen), Université Lille I, Ministere de l'Enseignement Supérieur, de la Recherche et de la Technologie, Centre National de la Recherche Scientifique (CNRS), Etablissement Regional de Transfusion Sanguine (ERTS) de Lille, MacoPharma Company, Tourcoing, France, and the Institute of Biochemistry of the Rumanian Academy, Bucharest, Rumania (to D Bratosin and J Montreuil), by doctoral fellowships from ECS (to F Petit), and from Delegation Generale de l'Armement (DGA) and FRM (to D Arnoult). We express our gratitude to Jocelyne Celen, Jacqueline Dondeyne, and Véronique Lebret for skilful assistance.

\section{References}

1. Hengartner $M(2000)$ The biochemistry of apoptosis. Nature 407: 770-776

2. Meier P, Finch A and Evan G (2000) Apoptosis in development. Nature 407: $796-801$

3. Savill J and Fadok V (2000) Corpse clearance defines the meaning of cell death. Nature 407: 784-788

4. Green DR (2000) Apoptotic pathways: Paper wraps stone blunt scissors. Cell 102: $1-4$

5. Desagher S and Martinou JC (2000) Mitochondria as the central control point of apoptosis. Trends Cell Biol. 10: 369-377

6. Martinou JC and Green D (2001) Breaking the mitochondrial barrier. Nature Rev. Mol. Cell Biol. 2: 63-67

7. Zamzami N and Kroemer G (2001) The mitochondrion in apoptosis: how Pandora's box opens. Nature Rev. Mol. Cell Biol. 2: 67-71

8. Krammer P (2000) CD95's deadly mission in the immune system. Nature 407: $789-795$

9. Green DR and Reed JC (1998) Mitochondria and apoptosis. Science 281:13091312

10. Kroemer G and Reed J (2000) Mitochondrial control of cell death. Nature Med. 6 : $513-519$

11. LiK, LiY, Shelton JM, Richardson JA, SpencerE, Chen ZJ, Wang X and Williams RS (2000) Cytochrome $c$ deficiency causes embryonic lethality and attenuates stress-induced apoptosis. Cell 101: $389-399$

12. Joza N, Susin SA, Daugas E, Stanford WL, Cho SK, Li CY, Sasaki T, Elia AJ, Cheng HY, Ravagnan L, Ferri KF, Zamzami N, Wakeham A, Hakem R, Yoshida $\mathrm{H}$, Kong YY, Mak TW, Zuniga-Pflucker JC, Kroemer G and Penninger JM (2001) Essential role of the mitochondrial apoptosis-inducing factor in programmed cell death. Nature 410: $549-554$

13. Raff MC (1992) Social controls on cell survival and cell death. Nature 356: $397-$ 400

14. Weil M, Jacobson MD, Coles HSR, Davies TJ, Gardner RL, Raff KD and Raff MC (1996) Constitutive expression of the machinery for programmed cell death. J. Cell Biol. 133: 1053

15. Schulze-OsthoffK, WalczakH, Droge W and KrammerP (1994) Cell nucleus and DNA fragmentation are not required for apoptosis. J. Cell Biol. 127: 15-20

16. Jacobson MD, Burne JF and Raff MC (1994) Programmed cell death and Bcl-2 protection in the absence of a nucleus. EMBO J. 13: 1899-1910

17. Wolf BB, Golstein JC, Stennicke HR, Beere H, Amarante-Mendes GP, Salvesen GS and Green DR (1999) Calpain functions in a caspase-independent manner to promote apoptotic-like events during platelet activation. Blood 94: 1683

18. Clark MR (1988) Senescence of red blood cells: progress and problems. Physiol Rev. 68: 503 
19. Boas FE, Forman L and Beutler E (1998) Phosphatidylserine exposure and red cell viability in red cell aging and in hemolytic anemia. Proc. Natl. Acad. Sci. USA 95: 3077

20. Bratosin D, Mazurier J, Tissier J, Estaquier J, Huart JJ, Ameisen JC, Aminoff D and Montreuil $J(1998)$ Cellular and molecular mechanisms of senescent erythrocyte phagocytosis by macrophages. (A review.) Biochimie 80: 173

21. Bessis M (1972) Red cell shape: An illustrated classification and its rationale. Nouv. Rev. Fr. Hematol. 12: 721

22. Fibach $E$ and Sharon $R$ (1991) Changes in $A B H$ antigen expression on red cells during in vivo aging: a flow cytometric analysis. Transfusion 34: 328

23. Bratosin D, Mazurier J, Tissier JP, Slomianny C, Estaquier J, Russo-Marie F Huart JJ, Freyssinet JM, Aminoff D, Ameisen JC and Montreuil J (1997) Molecular mechanisms of erythrophagocytosis. Characterization of the senescent erythrocytes that are phagocytized by macrophages. CR Acad. Sci. Paris 320: 811

24. Aiken NC, Satterlee JD and Galey WR(1992) Measurement of intracellular Ca2+ in young and old human erythrocytes using 19F-NMR spectroscopy. Biochim. Biophys. Acta 113: 155

25. Romero PJ and Romero EA (1999) Effect of cell ageing on Ca2+ influx into human red cells. Cell Calcium 26: 131

26. Kerr JFR, Willie AH and Currie AR (1972) Apoptosis: a basic biological phenomenon with wide-ranging implications in tissue kinetics. Br. J. Cancer 26: $239-257$

27. Jacobson MD, Weil M and Raff MC (1997) Programmed cell death in animal development. Cell 88: $347-354$

28. Zwaal RFA and Schroit AJ (1997) Pathophysiologic implications of membrane phospholipid aymmetry in blood cells. Blood 89: 1121

29. Thornberry NA and Lazebnik Y (1998) Caspases: enemies within. Science 281 $1312-1316$

30. Earnshaw WC, Martins LM and Kaufmann SH (1999) Mammalian caspases: structure, activation, substrates, and functions during apoptosis. Annu. Rev. Biochem. 68: 383-424
31. SquierMKT and Cohen JJ (1996) Calpain and cell death. Cell Death Differ. 3: 275

32. Wang KKW (2000) Calpain and caspases: can you tell the difference? Trends Neurosci. 23: 20

33. Michetti M, Salamino F, Minafra R, Melloni E and Pontremoli S (1997) Calciumbinding properties of human erythrocyte calpain. Biochem. J. 325: 721

34. Sahara S, Aoto M, Eguchi Y, Imamoto N, Yoneda Y and Tsujimoto Y (1999) Acinus is a caspase-3-activated protein required for apoptotic chromatin condensation. Nature 401: $168-173$

35. Nagata S (2000) Apoptotic DNA fragmentation. Exp. Cell Res. 256: $12-18$

36. Zermati Y, Garrido C, Amsellem S, Fishelson S, Bouscary D, Valensi F, Varet B, Solary $E$ and Hermine $O$ (2001) Caspase activation is required for terminal erythroid differentiation. J. Exp. Med. 193: 247-254

37. Sperandio S, deBelle I and Bredesen D (2000) An alternative non apoptotic form of programmed cell death. Proc. Natl. Acad. Sci. USA 97: 14376-14381

38. Wyllie AH and Golstein P (2001) More than one way to go. Proc. Natl. Acad. Sci. USA 98: $11-13$

39. Ameisen JC (1996) The origin of programmed cell death. Science 272: $1278-$ 1279

40. Ameisen JC (1998) The evolutionary origin and role of programmed cell death in single celled organisms: a new view of executioners, mitochondria, hostpathogen interactions, and the role of death in the process of natural selection. In When cells die, Lockshin R, Zakeri Z and Tilly J, eds (New York: Wiley-Liss, Inc.) pp. 3-56

41. Bratosin D, Mazurier J, Slomianny C, Aminoff D and Montreuil J(1997) Molecular mechanisms of erythrophagocytosis: flow cytometric quantitation of in vitro erythrocyte phagocytosis by macrophages. Cytometry 30: 269

42. Martin SJ, Finucane DM, Amarante-Mendes GP, O'Brien GA and Green DR (1996) Phosphatidylserine externalization during CD95-induced apoptosis of cells and cytoplasts requires ICE/CED-3 protease activity. J. Biol. Chem. 271: 28753 